\title{
Maternal socioeconomic characteristics and infant mortality from injuries in the Czech Republic 1989-92
}

\author{
Martin Bobak, Hynek Pikhart, Ilona Koupilová
}

\begin{abstract}
Objectives-Infant and childhood mortality from injuries in Central and Eastern Europe is high but little is known about its determinants. This study examined whether maternal socioeconomic characteristics predict infant mortality from injuries in the Czech Republic.

Methods-Data on all live births registered in the Czech Republic 1989-91 $(n=387496)$ were linked with the national death register, 1989-92, using the unique national identification number. Effects of maternal socioeconomic characteristics, birth weight and gestational age, recorded in the birth register, on the risk of death from external causes (ICD-9 800-999) were estimated using logistic regression.

Results-Of the 195 linked infant deaths from external causes (rate 50/100 000 live births), $73 \%$ were from suffocation. After controlling for other factors, the risk of death was higher in boys, declined with increasing maternal education (odds ratio for primary $v$ university education 3.5, $95 \%$ confidence interval 1.5 to 8.6 ), maternal age, birth weight and gestational age, and was increased in infants of unmarried mothers and of mothers with higher parity. The effect of education appeared stronger in married mothers and in mothers of low parity.

Conclusion-The risk of infant death from external causes in this population was strongly associated with maternal and family characteristics.

(Injury Prevention 2000;6:195-198)
\end{abstract}

Keywords: infant mortality; socioeconomic factors; Central and Eastern Europe

Childhood injuries and accidents are an important public health problem, posing a burden on health services but also leading to disabilities or death. There is evidence that in Western countries the rates of childhood injuries and accidents are more frequent in lower socioeconomic groups, ${ }^{12}$ in families with marital discord, ${ }^{3}$ and in areas with a higher level of deprivation. ${ }^{4}$ Few studies have addressed this question in detail, and little research has focused on deaths in infancy. Most prominent among them is a series of US studies which linked the birth and death records. ${ }^{5-10}$ All these studies found that a range of socioeconomic and demographic factors were strongly related to risk of death from injury in infancy or early childhood.

In this study, we analysed the effects of socioeconomic factors on infant mortality from injuries in a former communist country. This setting is appropriate. External causes are important contributors to the high mortality in Central and Eastern Europe in both adults ${ }^{11}$ and children. ${ }^{12} \mathrm{~A}$ recent report for Unicef found that in the age group 1-4 years, death rates from external causes in Central and Eastern Europe and the former Soviet Union were two and a half and five times higher, respectively, than in the European Union. ${ }^{12}$ Data reported to the World Health Organisation (WHO) show that infant mortality from injuries was several times higher in Central and Eastern Europe than in Western Europe (fig 1).

The objective of this study was to quantify the effects of different socioeconomic factors on risk of death from injuries, and to examine possible interactions between individual socioeconomic factors. To do this, we linked data from the birth and death registers in the Czech Republic to form a cohort of children born between 1989 and 1991 .

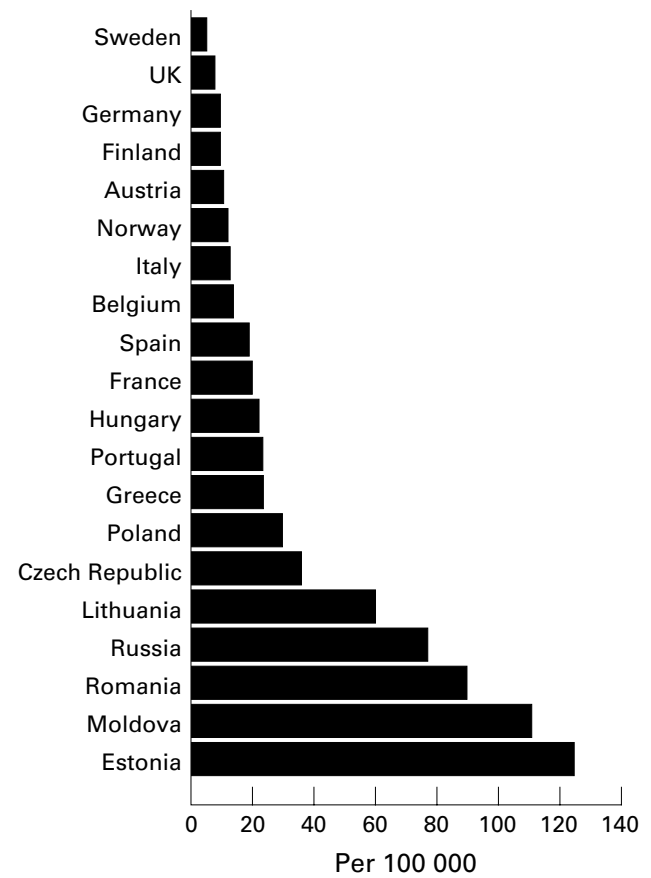

Figure 1 Infant mortality from external causes (per 100000 live births) in selected European countries in 1995 (data from $\mathrm{WHO}$ ). 
Table 1 Numbers (\%) of linked deaths from external causes in the Czech Republic, by cause of death (" $E$ " codes)

\begin{tabular}{ll}
\hline Cause of death & No (\%) \\
\hline Motor vehicle traffic accidents (E810-E819) & $9(5)$ \\
Accidental poisoning (E860-869) & $2(1)$ \\
Accidental falls (E880-E888) & $4(2)$ \\
Accidents caused by fire and flames (E890-E899) & $2(1)$ \\
Accidents due to nature and environmental factors (E900-E909) & $3(1)$ \\
Accidents caused by submersion, suffocation and foreign bodies (E910-915) & $143(73)$ \\
Inhalation and ingestion of food causing suffocation (E911) & $120(62)$ \\
Inhalation and ingestion of other object causing suffocation (E912) & $2(1)$ \\
Accidental mechanical suffocation (E913) & $21(11)$ \\
Other accidents (E916-E928) & $4(2)$ \\
Homicide and injuries purposely inflicted by other persons (E960-E969) & $15(8)$ \\
Injury undetermined whether accidentally or purposely inflicted (E980-E989) & $13(7)$ \\
Total (E800-E999) & $195(100)$ \\
\hline
\end{tabular}

\section{Methods}

We analysed national data on infant deaths occurring among all live births registered in the Czech Republic between 1989 and 1991. Birth registration data were linked to the death register, 1989-92, by national personal identity numbers. During that period, the WHO definition of live birth was used in the Czech Republic - that is, live born infants with a birth weight of $500 \mathrm{~g}$ or more were included in the register. The following information was available from the birth register: maternal age, maternal education, maternal marital status, nationality of mother and father, multiplicity, number of previous live births, birth weight, and gestational age.

The death register contained information on cause of death coded to the International Classification of Diseases, ninth revision (ICD-9) (including the supplementary E codes), and dates of birth and death. To comply with the

Table 2 Numbers of births, deaths from external causes, and death rates among infants in the cohort

\begin{tabular}{|c|c|c|c|}
\hline & No (\%) of births & No (\%) of deaths & $\begin{array}{l}\text { Rate/100 } 000 \text { ( } 95 \% \\
\text { confidence interval) }\end{array}$ \\
\hline Total & $387496(100)$ & $195(100)$ & $50(44$ to 58$)$ \\
\hline \multicolumn{4}{|c|}{ Sex of the infant } \\
\hline Girl & $188626(48.7)$ & $69(35.4)$ & $37(28$ to 46$)$ \\
\hline Boy & $198870(51.3)$ & $126(64.6)$ & $63(53$ to 75$)$ \\
\hline \multicolumn{4}{|c|}{ Education of mother } \\
\hline Primary & $53656(13.9)$ & $63(32.3)$ & $117(90$ to 150$)$ \\
\hline Vocational & $150753(38.9)$ & $88(45.1)$ & $58(47$ to 72$)$ \\
\hline Secondary & $148722(38.4)$ & $38(19.5)$ & $26(18$ to 35$)$ \\
\hline University & $34365(8.9)$ & $6(3.1)$ & 17 (6 to 38$)$ \\
\hline \multicolumn{4}{|c|}{ Nationality of mother } \\
\hline Czech & $366422(94.6)$ & $182(93.3)$ & $50(43$ to 57$)$ \\
\hline Other & $21074(5.4)$ & $13(6.7)$ & 62 (33 to 105$)$ \\
\hline \multicolumn{4}{|c|}{ Marital status of mother } \\
\hline Married & 353565 (91.2) & $149(76.4)$ & $42(36$ to 49$)$ \\
\hline Single & $24165(6.2)$ & $32(16.4)$ & $132(91$ to 187$)$ \\
\hline Divorced & $8753(2.3)$ & $12(6.2)$ & $137(71$ to 239$)$ \\
\hline Widowed & $1013(0.3)$ & $2(1.0)$ & $197(24$ to 711$)$ \\
\hline \multicolumn{4}{|c|}{ Maternal age (years) } \\
\hline$<20$ & $55817(14.4)$ & $41(21.0)$ & 73 (53 to 100 ) \\
\hline $20-24$ & $174403(45.0)$ & $90(46.2)$ & 52 (42 to 63$)$ \\
\hline $25-29$ & $103181(26.6)$ & $39(20.0)$ & $38(27$ to 52$)$ \\
\hline $30-34$ & $38399(9.9)$ & $15(7.7)$ & $39(22$ to 64$)$ \\
\hline $35+$ & $15696(4.1)$ & $10(5.1)$ & $64(31$ to 117$)$ \\
\hline \multicolumn{4}{|l|}{ Multiplicity } \\
\hline 1 & $380633(98.2)$ & $182(93.3)$ & $48(41$ to 55$)$ \\
\hline $2+$ & $6863(1.8)$ & $13(6.7)$ & $189(101$ to 324$)$ \\
\hline \multicolumn{4}{|l|}{ Birth order } \\
\hline 1 & $187613(48.4)$ & $80(41.0)$ & 43 (34 to 53$)$ \\
\hline 2 & $142126(36.7)$ & $68(34.9)$ & $48(37$ to 61$)$ \\
\hline $3+$ & $57757(14.9)$ & $47(24.1)$ & 81 (60 to 108$)$ \\
\hline \multicolumn{4}{|c|}{ Birth weight (g) } \\
\hline$<2500$ & $21348(5.5)$ & $23(11.8)$ & $108(68$ to 162$)$ \\
\hline $2500-3499$ & $223419(57.7)$ & $120(61.5)$ & $54(45$ to 64$)$ \\
\hline$\geqslant 3500$ & $142729(36.8)$ & $52(26.7)$ & $36(27$ to 48$)$ \\
\hline \multicolumn{4}{|c|}{ Gestational age (weeks) } \\
\hline$<38$ & $33613(8.7)$ & $35(18.0)$ & $104(73$ to 145$)$ \\
\hline$\geqslant 38$ & $353883(91.3)$ & $160(82.0)$ & $45(38$ to 53$)$ \\
\hline
\end{tabular}

data confidentiality law, linkage was conducted at the Czech Statistical Office. The linkage was successful for $86 \%$ of infant deaths. Although no formal evaluation of the quality of data from the Czech birth and death registers is available, the registers are virtually complete and the quality of the information is believed to be good. More than $97 \%$ of infants deaths had a postmortem examination.

All 195 deaths with ICD-9 codes 800-999 that could be linked with birth register were included in the present analyses. Logistic regression was used to study the variation in risk of infant death from external causes by socioeconomic factors. First, crude odds ratios were calculated for each independent variable. Then, all socioeconomic, demographic, and birth characteristics were entered into one model to assess their independent effects. The effect of birth weight and gestational age was approximately linear; therefore they were modelled as continuous variables. Because these two variables were strongly correlated, only one of these variables was entered in the full model. Finally, we tested for interactions between the socioeconomic and demographic variables.

\section{Results}

Among the 195 deaths from injuries and accidents that occurred in the cohort and that could be linked with their birth registration data, $170(87 \%)$ occurred in the postneonatal period (28-365 days), and 143 (73\%) were from obstruction of respiratory tract by food or from mechanical suffocation (E911-E913). Other causes of deaths were relatively rare (table 1). Table 2 shows the distribution of maternal characteristics and rates of deaths from injuries in the cohort. The overall rate was $50 / 100000$ live births.

Table 3 shows crude and adjusted odds ratios for the social and demographic characteristics of mothers and the indices of size at birth. Risk of death from external causes was significantly higher in boys than in girls (adjusted odds ratio 1.74, 95\% confidence interval 1.30 to 2.33 ). There was a strong inverse association with maternal education; after controlling for all covariates, infants born to mothers with primary education were about 3.5 times more likely to die from injuries than infants born to mothers with university education. Mother's nationality was not statistically significantly related to the outcome. However, maternal marital status was a strong predictor of injury deaths; mortality in infants of unmarried mothers was more than twice greater compared with married mothers. The association with maternal age was U-shaped in crude analyses, with the lowest risk among infants of mothers aged 25-34 years, but became nearly linear after adjustment for other risk factors. The risk of death was also strongly related to the number of previous live births and multiplicity. Low birth weight and low gestational age were also associated with increased risk of injury death; their effects were partly reduced by controlling for other factors, and were largely eliminated when both these 
Table 3 Odds ratios (95\% confidence intervals) of death from external causes (ICD-9 800-999) for socioeconomic and demographic variables

\begin{tabular}{|c|c|c|}
\hline & Crude & Fully adjustedt \\
\hline \multicolumn{3}{|l|}{ Sex of the infant } \\
\hline Girl & 1 & 1 \\
\hline Boy & $1.73(1.29$ to 2.32$)$ & $1.81(1.35$ to 2.43$)$ \\
\hline \multicolumn{3}{|l|}{ Education of mother } \\
\hline Primary & $6.73(2.91$ to 15.55$)$ & $3.53(1.45$ to 8.56$)$ \\
\hline Vocational & $3.34(1.46$ to 7.65$)$ & $2.30(0.98$ to 5.39$)$ \\
\hline Secondary & $1.46(0.62$ to 3.46$)$ & $1.16(0.48$ to 2.78$)$ \\
\hline University & 1 & 1 \\
\hline \multicolumn{3}{|c|}{ Nationality of mother } \\
\hline Czech & 1 & 1 \\
\hline Other & $1.24(0.71$ to 2.18$)$ & $0.67(0.37$ to 1.20$)$ \\
\hline \multicolumn{3}{|c|}{ Marital status of mother } \\
\hline Married & 1 & 1 \\
\hline Single & 3.15 (2.15 to 4.61$)$ & $2.17(1.40$ to 3.34$)$ \\
\hline Divorced & $3.26(1.81$ to 5.87$)$ & $2.28(1.22$ to 4.37$)$ \\
\hline Widowed & $4.69(1.16$ to 18.96$)$ & $3.24(0.77$ to 13.31$)$ \\
\hline \multicolumn{3}{|c|}{ Age of mother (years) } \\
\hline$<20$ & 1 & 1 \\
\hline $20-24$ & $0.70(0.49$ to 1.02$)$ & $0.84(0.55$ to 1.28$)$ \\
\hline $25-29$ & $0.51(0.33$ to 0.80$)$ & $0.55(0.32$ to 0.95$)$ \\
\hline $30-34$ & $0.53(0.29$ to 0.96$)$ & $0.41(0.20$ to 0.83$)$ \\
\hline $35+$ & $0.87(0.43$ to 1.73$)$ & $0.50(0.22$ to 1.13$)$ \\
\hline \multicolumn{3}{|l|}{ Multiplicity } \\
\hline 1 & 1 & 1 \\
\hline $2+$ & 3.97 (2.26 to 6.97$)$ & $2.63(1.42$ to 4.89$)$ \\
\hline \multicolumn{3}{|l|}{ Birth order } \\
\hline 1 & 1 & 1 \\
\hline 2 & $1.12(0.81$ to 1.55$)$ & $1.50(1.04$ to 2.16$)$ \\
\hline $3+$ & $1.91(1.33$ to 2.74$)$ & $2.21(1.35$ to 3.60$)$ \\
\hline \multicolumn{3}{|l|}{ Birth weight ${ }^{\star}$} \\
\hline $100 \mathrm{~g}$ increase & 0.95 (0.93 to 0.97$)$ & $0.97(0.95$ to 1.00$)$ \\
\hline \multicolumn{3}{|l|}{ Gestational age } \\
\hline 1 week increase & $0.88(0.83$ to 0.93$)$ & $0.93(0.88$ to 0.99$)$ \\
\hline
\end{tabular}

*Only one of these variables was included in the fully adjusted model.

tAdjusted for all variables in the table.

variables were included in the same model. Results were similar in the subset of deaths occurring in the postneonatal period and for deaths from suffocation (E911-E913, n=143).

Finally, we examined whether there were statistical interactions between the exposures under study in their effect on mortality from external causes in infancy. Two interactions were statistically significant after controlling for the other variables. The effect of education was seen among married but not among unmarried mothers $(p=0.002)$ and was more pronounced among mothers of low parity $(p=0.027)$. Conversely, the effects of marital status and parity were strongest among mothers with university education.

\section{Discussion}

We found that infant mortality from external causes was strongly related to several socioeconomic factors, and there appeared to be an interaction between marital status and parity on the one hand and education on the other.

\section{LIMITATIONS OF THE STUDY}

The socioeconomic characteristics used in this study are recorded at birth by the attending physician and/or nurse. Although some misclassification of the independent variables could have occurred, it was probably small and random. An autopsy was done on $97 \%$ of infant deaths from injury; therefore a serious misclassification of the outcome seems unlikely, although the rates of suffocation were much higher than in the US. ${ }^{5}$ However, the high rates of suffocation are not restricted to the Czech Republic. We found a similar pattern in Estonia, where $66 \%$ of all infant injury deaths were from suffocation, and of these, 95\% were from inhalation or ingestion of food (I Koupilova, unpublished). Although some intentional deaths and, perhaps, some deaths from sudden infant death syndrome, may have been incorrectly classified as suffocation, this is unlikely to influence substantially the observed pattern of increased rates of injury deaths in infants of mothers with lower socioeconomic status.

The main source of bias in this study are the $14 \%$ of unlinked deaths. If the unlinked deaths were related to socioeconomic status, they could potentially affect the validity of our findings. However, the unlinked deaths were mostly deaths in the first hours or days of life, and caused by complications of pregnancy, childbirth, and the puerperium (ICD-9 630639) or by conditions originating in the perinatal period (ICD-9 760-779). Only 22 unlinked deaths were from external causes. Unfortunately, we were not provided with more information on these deaths by the Statistical Office. However, it is unlikely that these deaths would come predominantly from higher socioeconomic groups; in fact, one would expect the opposite. We think, therefore, that it is unlikely that linkage bias could seriously affect our results.

\section{CONSISTENCY WITH OTHER STUDIES}

The variation in infant mortality from injury by maternal socioeconomic status was considerable. Except for the nationality of the mother, all variables used in the analyses were related to mortality. This is consistent with US linkage studies $^{5-10}$ and with reports based on grouped data in Western countries. ${ }^{1-4}$ The steep gradient by maternal education is consistent with other studies ${ }^{5-10}$ and is also in agreement with previous studies of birth weight, ${ }^{13}$ infant mortality, ${ }^{14}$ or child growth ${ }^{15}$ in the Czech Republic. Maternal marital status, maternal age, and the number of previous live births (as a proxy for the number of children in a family) have all been previously found to strongly influence mortality from injuries in infants ${ }^{5-8} 10$ and in young children. ${ }^{9}$ A strong association between number of children in the household and injuries was also reported for children aged 5-10 years. ${ }^{16}$ Both birth weight and gestational age were associated with infant injury deaths in the US, with a similar magnitude of the effects. ${ }^{5}$

EXPLANATIONS FOR THE SOCIAL GRADIENT

Given that most deaths were from inhaling foods and foreign objects and mechanical suffocation, material circumstances such as poor housing are an unlikely explanation for the large gradients. Moreover, education in the Czech Republic has been only weakly correlated to income ${ }^{17}$ or material conditions, such as housing or car ownership. ${ }^{15}$ It is difficult, however, to identify the "main" risk factor. Low maternal education or being a single mother may be only indirect measures of the proximal causal factor(s). Similarly, it is likely that birth weight and gestational age reflect, at large, maternal or family socioeconomic envi- 
ronment, rather than being causally related to injury deaths.

We speculate that the factors related to risk of death in our data may represent two broad areas. Maternal age and maternal education may reflect knowledge and experience related to child care. The second area, in our data represented by marital status, parity and multiplicity, may reflect the attention and "person-time" available for child care. Intuitively, each of these aspects would seem to be important for the risk of infant injuries. The interaction between maternal education, on the one hand, and parity and marital status on the other, may reflect an interaction between these two dimensions of child care.

The direction of the interaction was unexpected, however. Beforehand, we had hypothesised that education might buffer the lack of time or "manpower" to supervise an infant. The results point to the opposite. They indicate that better educated mothers are more likely than mothers with low education to avoid infant injuries under the optimal conditions, for example when they have enough time for the child. Under less favourable conditions, for example in the absence of a husband or when there are other children competing for attention, the protective effect of education was not observed. However, it would be premature to draw firm conclusions from these interactions. The number of deaths from external causes in our data was small, and the interactions may be due to random error. Moreover, unmeasured factors, such as mother's work outside home and use of child care, may have contributed to the pattern of the interactions observed. This speculation, therefore, needs confirmation in independent studies.

\section{POLICY IMPLICATIONS}

External causes are not a major source of death in infancy, not even in Central and Eastern Europe, where they account for some $6 \%$ of all infant deaths, and for up to $20 \%$ of deaths in the postneonatal period. However, because they may be largely preventable, they are a potentially important area for action. Not all socioeconomic differences can be removed by a prevention policy but the population attributable fraction may provide a guide to the potential effect of such policies. For example, using the unadjusted odds ratios, about $65 \%$ of external deaths are statistically attributable to maternal education alone, and may, theoretically, be preventable. This is similar to the US estimate that some three quarters of injury deaths in childhood could be avoided if the rates were equal to a low risk group (with the most favourable socioeconomic characteristics). ${ }^{9}$

In our view, the results suggest that infant deaths from injury cluster in subpopulations characterised by social disadvantage. Such groups seem an obvious target for intervention. Given the nature of external deaths, prevention programmes should not require expensive technology. As the first step, a surveillance programme of injuries in infancy and childhood should be established, and specific studies should assess the circumstances associated with injury deaths.

If the data on causes of death are correct, over half of infant deaths from injury in the Czech Republic were from inhalation and/or ingestion of food. This points towards inadequate parental supervision and feeding practices. In the Czech Republic, each newborn is registered with a general practitioner and local pediatrician, and mothers are regularly invited for check-ups and vaccination visits. A brief educational intervention by health professionals during such visits would be feasible. The intervention could be targeted preferentially to single mothers or mothers in difficult social circumstances.

While there are always competing claims for the attention of policy makers, we believe that the problem of injuries in Central and Eastern Europe has many features that should enable it to move up the policy agenda. Most Western countries have achieved remarkable successes in reducing injury mortality in infancy and childhood. These countries have also demonstrated many features of appropriate policy action, from which Eastern European countries can learn: the importance of raising the public profile of injuries, the central role of concerned civil society organisations, and the importance of making the issue visible.

The authors would like to thank to Mr M Simek at the Czech Statistical Office for linking the birth and death registration data.

1 Black D, Morris JN, Smith C, et al. Inequalities in health: the health divide. (Black report.) London: Penguin Group, 1992 .

2 Nathorst-Westfelt JA. Environmental factors in childhood accidents: a prospective study in Goteborg, Sweden. Acta accidents: a prospective study in Goteb

3 Husband P, Hinton PE. Families of children with repeated accidents. Arch Dis Child 1972;47:396-400.

4 Roberts I, Marshall R, Norton R, et al. An area analysis of child injury morbidity in Auckland. $\mathcal{F}$ Paediatr Child Health 1992;28:438-41.

5 Brenner RA, Overpeck MD, Trumble AC, et al. Deaths attributable to injuries in infants, United States, 19831991. Pediatrics 1999;103:968-74.

6 Overpeck MD, Brenner RA, Trumble AC, et al. Risk factors for infant homicide in the United States. $N$ Engl $\mathcal{F}$ Med 1998;339:1211-16.

7 Scholer SJ, Hickson GB, Ray WA. Sociodemographic factors identify US infants at high risk of injury mortality. Pediatrics 1999;103:1183-8.

8 Scholer SJ, Hickson GB, Mitchel EFJ, et al. Persistently increased injury mortality rates in high-risk young children. Arch Pediatr Adolesc Med 1997;151:1216-19.

9 Scholer SJ, Mitchel EFJ, Ray WA. Predictors of injury mortality in early childhood. Pediatrics 1997;100:342-7.

10 Cummings $\mathrm{P}$, Theis MK, Mueller BA, et al. Infant injury death in Washington State, 1981 through 1990. Arch Pediatr Adolesc Med 1994;148:1021-6.

11 Bobak M, Marmot M. East-west mortality divide and its potential explanations: proposed research agenda. BMF 1996;312:421-5.

12 European Centre on Health of Societies in Transition (ECOHOST). Childhood injuries. A priority area for the transition countries of Central and Eastern Europe and the newly independent states. Final report to Unicef. London: London School of Hygiene and Tropical Medicine, 1998.

13 Koupilova I, Vagero D, Leon DA, et al. Social variation in size at birth and preterm delivery in the Czech Republic and Sweden, 1989-1991. Paediatr Perinatal Epidemiol 1998;12:7-24.

14 Koupilova I, Bobak M, Holcik J, et al. Increasing social variation in birth outcome in the Czech Republic after 1989. ation in birth outcome in the Czech

15 Bobak M, Kriz B, Leon DA, et al. Socioeconomic factors and height of preschool children in the Czech Republic. Am F Public Health 1994;84:1167-70.

6 Bijur PE, Golding J, Kurzon M. Childhood accidents, family size and birth order. Soc Sci Med 1988;26:839-43.

17 Machonin P, Tucek M. Ceska spolecnost $v$ transformaci (Czech society in transformation) [in Czech]. Prague: Sociologicke nakladatelstvi, 1996. 